\title{
Knowledge production through collaborative research in sub-Saharan Africa: how much do countries contribute to each other's knowledge output and citation impact?
}

\author{
Omwoyo Bosire Onyancha $\cdot$ Jan Resenga Maluleka
}

Received: 15 September 2010

(C) Akadémiai Kiadó, Budapest, Hungary 2011

\begin{abstract}
This paper examines co-authorship of research articles in Thomson Reuters citation indexes in order to assess knowledge co-production in selected sub-Saharan African countries. Two indicators, namely publications and citations, were analysed to establish the patterns of knowledge co-production and its scientific impact, respectively. The study found that knowledge production through collaborative research among subSaharan African countries is minimal and contributes only a small percentage when compared to collaboration between sub-Saharan African countries and their foreign counterparts. Similarly, the scientific impact of international collaboration was higher than that of continental collaboration. Countries belonging to the same geographic region contributed to each other's knowledge production more frequently than they did to the countries outside their region. It is recommended that, for knowledge co-production in subSaharan Africa to improve, various measures such as encouraging student and staff exchange, hosting more regional conferences and encouraging research networks need to be put in place.
\end{abstract}

Keywords Research collaboration - Knowledge production - Sub-Saharan Africa · Citation impact

\section{Introduction}

Although Huff (2000, p. 291) alludes to a third mode of knowledge production, namely Mode 1.5 , it is generally agreed that there are two modes of knowledge production. A lot has been written about Mode 1 and Mode 2 types or paradigms of knowledge production (see Gerber 2005; Gibbons et al. 1994; Le Grange 2005; Jacob 2000). Gerber (2005) and

O. B. Onyancha $(\bowtie) \cdot$ J. R. Maluleka

Department of Information Science, University of South Africa, Unisa, 392, Pretoria 0003,

South Africa

e-mail: b_onyancha@yahoo.com; onyanob@unisa.ac.za

J. R. Maluleka

e-mail: malulrj@unisa.ac.za 
Moravec (2007) distinguish the two modes by observing that, whereas Mode 1 deals with disciplinary knowledge, Mode 2 focuses on problem-solving knowledge production. Gerber (2005, p. 1398) further notes that unlike Mode 1, which produces disciplinary knowledge which is "developed in a disciplinary, primarily cognitive context,... followed by strong cognitive and social norms and processes that must be followed in production, legitimation and diffusion of knowledge", Mode 2 produces "transdisciplinary knowledge, which is created in transdisciplinary, social and economic contexts and organised around a particular application". In his explanation of Mode 2 knowledge production, Muller in Gerber (2005, p. 1399) observes that:

Mode 2 knowledge production is characterised by a form of social organisation which differs from traditional, pure or applied research. This implies that the problem arises in a context of application and as problem-solving research it is transdisciplinary, trans-institutional and financed by more than one source. This leads to a more collaborative research structure than the traditional research team. Quality of research is increasingly being assessed against hybrid, contextually relevant criteria.

Despite their differences, both Mode 1 and Mode 2 knowledge are important as the former forms the foundation for the latter while the latter supplements the former in a "pattern of co-evolution between the two" (Gerber 2005, p. 1396). However, going by the current trends, Mode 2 knowledge production is increasingly being promoted, especially in regard to research at institutions of higher learning more particularly in developing countries, perhaps because it encourages research collaboration which in turn can lead to high quality research. As Lundberg (2006, p. 20) argues, "it is not unreasonable to believe that high quality research involves a larger number [of] collaborating organizations (or countries) than low quality research". The importance of knowledge production cannot therefore be overemphasized. Egbu (2006, p. 304) has summarized the importance of knowledge production in an organization thus: "the main triggers of knowledge production in the construction industry are: the need to effectively deal with complex projects; the effective use of new, innovative building materials, systems, services; managing change (both project change and organizational change); coping with the uniqueness of projects; and managing team member interfaces (e.g., consultant-contractor)". These factors, we believe, apply to knowledge production in other institutions engaged with the practice of producing knowledge in any given country.

Moravec (2007, p. 35) points out that "knowledge production is no longer dependent primarily on researchers, but is also present in public spaces of individual scientific creativity, the space between science and ethno-science, professional and lay knowledge, the market, and public discourse". On her part, Knorr-Certina in Moravec (2007) argues that knowledge is produced through cultural activities or scientific methods. Several authors (Arocena and Sutz 2001; Imeda 2005; Gerber 2005; Moravec 2007) have also connected knowledge production to formal education offered at higher institutions of learning including universities. Egbu (2006) concedes that knowledge production can occur through a variety of ways, including reflective practice and the transformation and combination of existing knowledge. However, it is widely acknowledged that research is the most common method through which knowledge is produced (Egbu 2006; Imeda 2005). In fact, most published literature discusses knowledge production in terms of research and industrial innovation (e.g., Aeberhard and Rist 2008; Arocena and Sutz 2001; Frenken 2002; Hessels and van Lente 2008; Russell and Rousseau n.d.; Schneider et al. 2006; Wessels 2006). The 
said research can be basic or applied, disciplinary or interdisciplinary, sole or collaborative, or industry- or university-based.

In view of the fact that knowledge production takes place mainly through research activities, it is safe to conclude that, just as is the case with collaborative research, collaborative knowledge production among individuals, institutions and countries is a worthy endeavour. Onyancha and Ocholla (2007, p. 239) observe that research collaboration is beneficial in that it enables researchers to share knowledge, skills and techniques; it makes it possible to transfer tacit knowledge; it provides intellectual companionship; it plugs the researcher into a wider network of contacts in the scientific community; and it enhances the potential visibility of a work as well as reducing the costs of research. Abramo et al. (2009), Frenken (2002) and Sooryamoorthy (2009) have also observed that collaborative research not only leads to an increase in knowledge production but also encourages knowledge sharing among the participating researchers. Klitkou et al. (2009, p. 2) opine that "project cooperation between research institutions, industry and long-term partnerships in networks of excellence where industry and research institutions pool their resources, and improved knowledge transfer between public research and industry contribute effectively to the effective knowledge sharing between public science and industry". Hoekman et al. (2009, p. 723), too, observe that "the relevance of collaboration is evidenced by the fact that the number of citations that scientific articles receive increases with the number of contributing researchers".

These benefits notwithstanding, Africa is said to be contributing only a small percentage towards global knowledge production and impact (Adams et al. 2010; Arvanitis et al. 2000; Boshoff 2009; Narvaez-Berthelemot et al. 2002; Onyancha and Ocholla 2007). For instance, Adams et al. (2010, p. 10) summarize their findings in the Global Research Report thus: Africa's "volume of activity remains small, much smaller than is desirable if the potential contribution of Africa's researchers is to be realized for the benefit of its populations". Boshoff (2009) notes that sub-Saharan Africa's share of world scientific papers was $1 \%$ in 1987 and has continued to decrease to stand at $0.7 \%$ in 1996 . As a whole, Africa's world share of scientific papers was $1.8 \%$ between 2000 and 2004 (Pouris and Pouris as cited in Boshoff 2009). In regard to research collaboration, the aforementioned studies indicate that African countries are increasingly embracing international collaboration. This pattern is in tandem with Hoekman et al.'s (2010, p. 2) observation that "scientific knowledge creation is increasingly dependent on collaborative efforts". North Africa's foreign collaborators, for instance, include France, Germany, Italy, Spain, and the UK, a situation that has been attributed to North Africa's strong historical ties with those countries. Anglophone Africa, on the other hand, tends to collaborate with the USA and the UK. Adams et al. (2010) explain that the USA is the most collaborative partner with Anglophone countries mainly because "researchers who have studied in the USA maintain links with those research groups when they return home". Although a few studies (e.g., Adams et al. 2010; Narvaez-Berthelemot et al. 2002; Onyancha and Ocholla 2007; Onyancha 2009) have examined continental collaboration (i.e., collaboration among African countries), there is still no comprehensive study that has been conducted to assess the patterns and impact of research collaboration among the African countries.

As mentioned above, there are several ways through which knowledge can be produced in and/or by a given entity. These approaches include formal research and reflective practice (Egbu 2006). This study is limited to knowledge production through research. Worldwide, studies have been conducted to assess knowledge production in terms of research output and impact, which are in turn measured by way of counting the number of publications and citations, respectively. Examples of the studies that have specifically 
adopted the counting of publications to measure knowledge production in particular disciplines in given geographic regions include Choung et al. (2003), who set out to examine patterns of knowledge production in the information and telecommunication sectors in Korea. Collazo-Reyes et al. (2010) examined how knowledge production patterns of Mexican physics in particles and fields can be enriched. In their article entitled "The place of universities in the system of knowledge production", Godin and Gingras (2000, p. 274) measured the presence of universities in the system of knowledge production by examining the participation of at least one university in a given paper and concluded that "universities remain at the center of the system, while growth of the other sectors (hospitals, industries and government laboratories) is strongly linked to universities". The study on "The geography of collaborative knowledge production in Europe" by Hoekman et al. (2009) investigated inter-regional research collaboration as measured by scientific publications and patents with multiple addresses. Other studies that have used publications as indicators of knowledge production in a given country include Hayashi and Fujigaki (1999), Heinze and Kuhlmann (2008), Jansen et al. (2010), Prpic (2007), and Ranga et al. (2003).

This study reports preliminary findings of an informetric study of knowledge production through collaborative research in selected countries in sub-Saharan Africa. The study examines the patterns and impact of research collaboration in selected countries in order to find out the effect of continental and international research collaboration on a country's research productivity (knowledge production) and impact. The study seeks to answer the following research questions:

1. How much do individual sub-Saharan African countries contribute to one another's knowledge production and impact?

2. How much do African countries (aggregated) contribute to fellow sub-Saharan African countries in terms of research output and impact?

3. How much do foreign countries (i.e., countries outside Africa) contribute to subSaharan African countries in terms of knowledge production and impact?

4. What is the pattern of collaboration in knowledge production in sub-Saharan Africa?

\section{Methodology}

In order to assess the extent and impact of knowledge co-production among sub-Saharan African countries, an analysis of the contributions of a selected number of countries to each other's publications output and citation impact was conducted. Fifteen most productive countries, in terms of the number of published articles, were selected for the current study. Data was extracted from the Thomson Reuters citation indexes, namely: Arts and Humanities Citation Index (A\&HCI); Science Citation Index (SCI); and Social Sciences Citation Index (SSCI). The search query, CU = Country name, where the field tag CU stands for the author's country of affiliation, was used to download relevant data. The search was limited to articles published between 1995 and 2008. The choice of the starting year of publication was determined on the basis that South Africa, which was among the countries investigated in this study, was re-admitted into the scientific arena upon its attainment of democratic government (Government of National Unity) in 1994. For a balanced analysis of research collaboration among the countries, therefore, it was necessary to investigate the publications published after 1994. Once the search was performed, the data was subjected to analysis using the Thomson Reuters Analyze option to obtain frequencies of occurrence in the three databases. Each country's total research output was 
determined by the total number of articles published between 1995 and 2008, after cleaning the data from other publication types and publications published outside the period of study. Table 2 provides the names of countries in sub-Saharan Africa with the corresponding number of articles published by each country. Since visualizing each of the 47 sub-Saharan African countries' contribution to one another's knowledge production proved difficult when it came to presenting the relationships in tabular format, we chose to select 15 most productive countries as a case study for this paper (see Table 1).

Once the countries to be investigated were selected, the articles belonging to a given country (herein referred to as Country B) were analyzed by country of publication in order to identify another country (herein referred to as Country A) that participated in the publication of Country B's articles. The assumption was that Country A's presence in publications authored by Country B implied that the former contributed to the latter's knowledge production and impact and vice versa. Two approaches were employed to find out Country A's contribution to Country B's research output, and hence to knowledge production.

Approach 1: Unique items specific to country A (i.e., articles that contained names of only Country A besides Country B within the authors' addresses of Country B's publications) were obtained by excluding the rest of the countries from the list of contributing countries and remaining with only the country under investigation (Country B) and the selected country (Country A) as shown in Fig. 1. Excluding the other countries (by clicking on the Exclude Records button) and remaining with only two countries from the list of countries ensured that only publications that belonged to the unmarked countries were obtained. The example in Fig. 1 meant that only South African (Country B) papers that bore only "Sudan" (Country A) and "South Africa" in the author's address field were counted. The frequency of Country A's occurrence (as the author) in Country B's publications was used to measure the latter's contribution in the former's knowledge production through research output. For example, if Country A appeared

Table 1 Names of selected countries and their codes (Country codes are according to the International Organization for Standardization (ISO standards) which were obtained from: http://www.mathguide.de/info/ tools/countrycode.html, (accessed 4 December 2009)

\begin{tabular}{ll}
\hline Country & Code (ISO) \\
\hline Botswana & BW \\
Burkina Faso & BF \\
Cameroon & CM \\
Cote d'Ivoire & CI \\
Ethiopia & ET \\
Ghana & GH \\
Kenya & KE \\
Malawi & MW \\
Nigeria & NG \\
Senegal & SN \\
South Africa & ZA \\
Sudan & SD \\
Tanzania & TZ \\
Uganda & UG \\
Zimbabwe & ZW \\
\hline
\end{tabular}




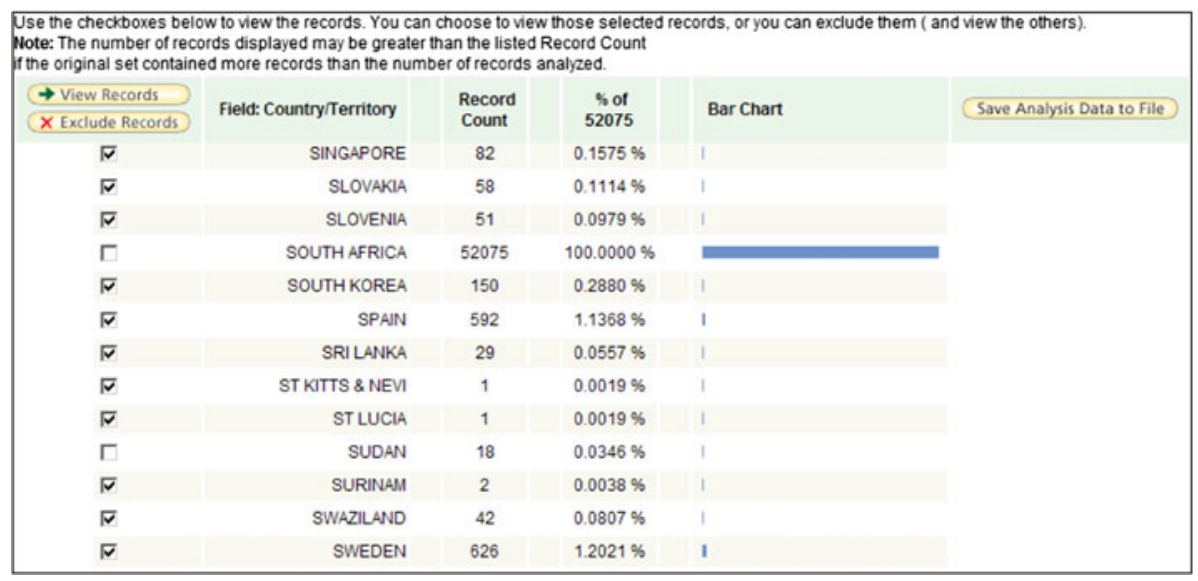

Fig. 1 Filtering of unique items co-authored by Country A and Country B

100 times as the author in Country B's total number of 1,000 articles, then Country A was said to have contributed $10 \%$ of Country B's knowledge production.

Approach 2: In order to obtain ALL articles in which Country A appeared in Country B's publications, only the affected country (i.e., Country A) was checked (or selected) from the list of countries and the View Records button clicked. The purpose of this analysis was to obtain a list of all countries that partnered with Country A to conduct research with Country B.

Similarly, in assessing Country A's contribution to Country B's research impact (i.e., impact associated with knowledge co-production among the affected countries), Country A's sole (Approach 1) and aggregated (Approach 2) articles in Country B's articles were subjected to a citation analysis in order to obtain the number of citations that Country A generated together with Country B between 1995 and 2008. The average cites per paper was also computed based on the unique and aggregated articles and compared to a country's (i.e., Country B's) sole cites per paper to determine whether or not a country's impact is positively affected by collaboration.

Essentially, the purpose of all the aforementioned analytical processes was to measure Country A's sole (Approach 1) and aggregated (Approach 2) contribution to Country B's research output and impact. The same approach was used to find out the effect of continental and international research collaboration on a given country's total research output and impact (see Table 7). This was achieved by grouping the countries into two categories. The first category consisted of African countries (continental) while the second category comprised countries outside Africa (labelled as 'international').

Finally, a core/periphery model analysis was conducted to determine the countries that contributed the most number of articles to each other's total publications output and those countries that had minimal collaborations with the selected countries. The former category of countries formed the core while the latter formed the peripheral class. The core/ periphery model identifies which actors belong in the core and which belong in the periphery (Borgatti et al. 2002). The analysis was done using version 6 of UCINET for Windows. 


\section{Findings and discussion}

The findings of this study are presented and discussed under the following sub-headings:

1. Research output in sub-Saharan Africa

2. Contributions of selected sub-Saharan African countries to each other's research output

3. Contributions of selected sub-Saharan African countries to each other's citation impact

4. Comparison of internal, regional and international research output and impact

5. Core/periphery model of selected participants.

\section{Research output in sub-Saharan Africa}

Table 1 provides the number of research articles that each of the sub-Saharan African country produced between 1995 and 2008. South Africa led the pack with a total of 52,098 articles, followed by Nigeria (12,759), Kenya (7,529), Tanzania $(3,552)$, and Ethiopia $(3,499)$, while Cameroon came in sixth position with a total of 3,407 articles. The rest of the countries produced fewer than 3,000 research articles between 1995 and 2008. There were 7 countries which produced fewer than 100 articles each, while 9 countries yielded between 100 and 200 articles each. Out of the 47 countries listed in the table, 14 produced between 200 and 1,000 research articles each and 11 produced between 1,000 and 3,000 articles each. Most countries, therefore, produced less than 1,000 articles each.

The findings in Table 2 concur with the findings of a study conducted by NarvaezBerthelemot et al. (2002) who also noted that South Africa was the most productive African country in science between 1991 and 1997. In their explanation of this pattern of research productivity of African countries, Narvaez-Berthelemot et al. (2002, p. 239) cited a report of the World Bank which considered South Africa among the scientifically proficient countries in terms of "weighted S \& T composite index including such parameters as GNP per capita, expenditure on $\mathrm{R} \& \mathrm{D}$, and numbers of $\mathrm{S} \& \mathrm{~T}$ journal articles and patents". The World Bank report classified all the other African countries as scientifically lagging countries. Data available on the World Bank's website on research and development expenditure shows that South Africa spent about $1 \%$ of its Gross Domestic Product (GDP) on research and development in 2006. South Africa's GDP during that period was the highest in Africa and stood at USD 2,83,007. Other African countries whose R \& D expenditures are made available at the World Bank's website include Uganda ( $0.04 \%$ in 2007), Democratic Republic of Congo (0.05\% in 2005), Burkina Faso (0.1\% in 2007), Senegal $(0.1 \%)$, Sudan $(0.3 \%$ in 2007$)$ and Ethiopia (0.2\% in 2007). There is a lack of information regarding other sub-Saharan African countries' expenditures on R \& D. Comparatively, such countries as Israel, Australia, Singapore, Republic of Korea, and Japan have committed between 1.8 and $3.5 \%$ of their GDP to R \& D. Another factor that may be influencing South Africa's high research output is the number of researchers. According to the World Bank indicators, South Africa had 382 researchers per one million people in 2005, followed by Senegal (276), Cote d'Ivoire (66), Mali (42), Togo (34), Ethiopia (21), and Niger (7.7). Similar data for other sub-Saharan African countries was not available. Finally, several studies (e.g., Cybermetrics Lab. Consejo Superior de Investigaciones Científicas (CSIC) 2010) have shown that South African universities are highly ranked when it comes to research. In fact, of the top 10 positions in Africa, South 
O. B. Onyancha, J. R. Maluleka

Table 2 Number of articles per country, 1995-2008

\begin{tabular}{|c|c|c|}
\hline Rank & Country & $\begin{array}{l}\text { Number } \\
\text { of articles }\end{array}$ \\
\hline 1 & South Africa & 52,098 \\
\hline 2 & Nigeria & 12,759 \\
\hline 3 & Kenya & 7,529 \\
\hline 4 & Tanzania & 3,552 \\
\hline 5 & Ethiopia & 3,499 \\
\hline 6 & Cameroon & 3,407 \\
\hline 7 & Uganda & 2,677 \\
\hline 8 & Zimbabwe & 2,638 \\
\hline 9 & Ghana & 2,518 \\
\hline 10 & Senegal & 2,388 \\
\hline 11 & Cote d'Ivoire & 1,680 \\
\hline 12 & Botswana & 1,481 \\
\hline 13 & Malawi & 1,427 \\
\hline 14 & Sudan & 1,367 \\
\hline 15 & Burkina Faso & 1,310 \\
\hline 16 & Zambia & 1,135 \\
\hline 17 & Benin & 1,021 \\
\hline 18 & Gambia & 838 \\
\hline 19 & Gabon & 765 \\
\hline 20 & Mali & 749 \\
\hline 21 & Madagascar & 739 \\
\hline 22 & Namibia & 626 \\
\hline 23 & Niger & 609 \\
\hline 24 & Mozambique & 552 \\
\hline 25 & Republic of the Congo (Brazzaville) & 542 \\
\hline 26 & Mauritius & 475 \\
\hline 27 & Togo & 405 \\
\hline 28 & Democrat Rep Congo (former Zaire) & 340 \\
\hline 29 & Eritrea & 228 \\
\hline 30 & Guinea-Bissau & 216 \\
\hline 31 & Rwanda & 207 \\
\hline 32 & Swaziland & 180 \\
\hline 33 & Mauritania & 179 \\
\hline 34 & Guinea & 160 \\
\hline 35 & Seychelles & 148 \\
\hline 36 & Burundi & 141 \\
\hline 37 & Chad & 138 \\
\hline 38 & Angola & 137 \\
\hline 39 & Sierra Leone & 122 \\
\hline 40 & Lesotho & 105 \\
\hline 41 & Equatorial Guinea & 31 \\
\hline 42 & Liberia & 31 \\
\hline 43 & Comoros & 27 \\
\hline 44 & Djibouti & 23 \\
\hline
\end{tabular}


Table 2 continued

\begin{tabular}{lll}
\hline Rank & Country & $\begin{array}{l}\text { Number } \\
\text { of articles }\end{array}$ \\
\hline 45 & Cape Verde & 20 \\
46 & Sao Tome and Principe & 17 \\
47 & Somalia & 16 \\
\hline
\end{tabular}

Africa's universities occupy the first 9 positions. There are 23 state universities in South Africa.

\section{Contributions of selected countries to each other's research output}

This section covers a country's sole and aggregated contribution to one another. Respectively, Tables 3 and 4 provide Country A's sole and aggregated contributions to Country B's research output. The figures in closed brackets represent the percentage contribution of Country A to Country B's research output based on Country B's total research output presented in the last row. It was noted that South Africa, on its own, contributed 5.4 and 5.3\% to Zimbabwe's and Botswana's total research output, respectively. In actual fact, it was only South Africa that surpassed 5\% contribution to any other country in the first case, i.e., countries' sole contributions. Other contributions that were somewhat high, in the order of number of articles and percentages of Country B's total research output, included: South Africa to Ethiopia (99, 2.8\%), South Africa to Malawi $(35,2.5 \%)$, Cameroon to Botswana $(23,1.6 \%)$, South Africa to Uganda (44, 1.6\%), Nigeria to Botswana $(21,1.4 \%)$, Kenya to Uganda $(37,1.4 \%)$, Senegal to Burkina Faso $(18,1.4 \%)$, South Africa to Nigeria (165, 1.3\%), South Africa to Kenya (94, 1.2\%), Nigeria to Cameroon (40, 1.2\%), Kenya to Ethiopia (40, 1.1\%), and Kenya to Sudan (15, 1.1\%). Other contributions registered a low percentage of between 0 and $1 \%$ of the total research output of a given country, with regard to sole contributions.

In terms of aggregated contributions, it was noted that the highest percentage contribution of articles was made by South Africa to Zimbabwe (i.e., 308 articles or $11.7 \%$ of Zimbabwe's total research output), a percentage increment of $6.3 \%$ on South Africa's sole contribution to Zimbabwe during the same study period. Botswana's collaboration with South Africa resulted in a total of 159 articles, accounting for $10.7 \%$ of Botswana's total research output. This was closely followed by Kenya's contribution to Uganda (201, 7.5\%), Senegal's contribution to Burkina Faso (93, 7.1\%), South Africa's contribution to Malawi $(91,6.4 \%)$ and Kenya's contribution to Tanzania $(179,5.0 \%)$. This pattern of collaboration was also reported by Adams et al. (2010) in their global research report on Africa, which revealed that countries belonging to the same geographic region tended to collaborate more with each other than they did with countries outside their regions.

The above analysis reveals a pattern that some other previous studies have found, which is that a country's total research output is greatly boosted by its neighbours (Onyancha and Ocholla 2007; Hoekman et al. 2010). Geographical proximity therefore plays a big role in a given country's knowledge production in terms of research output. This pattern may also reflect countries that are engaged in empowering others in terms of skills and technological transfer and countries in which citizens of other countries acquire knowledge or are trained. In the case of the countries that train citizens of other countries, South Africa attracts a 


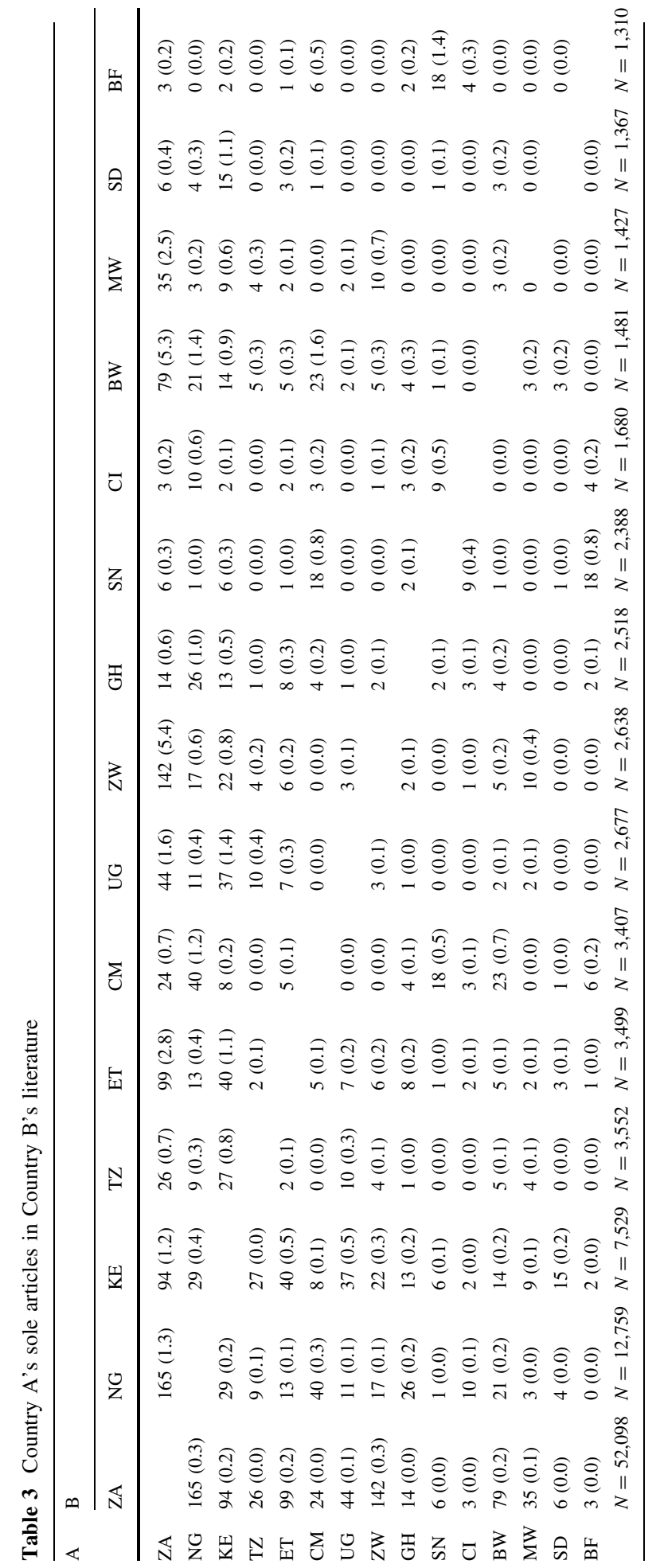




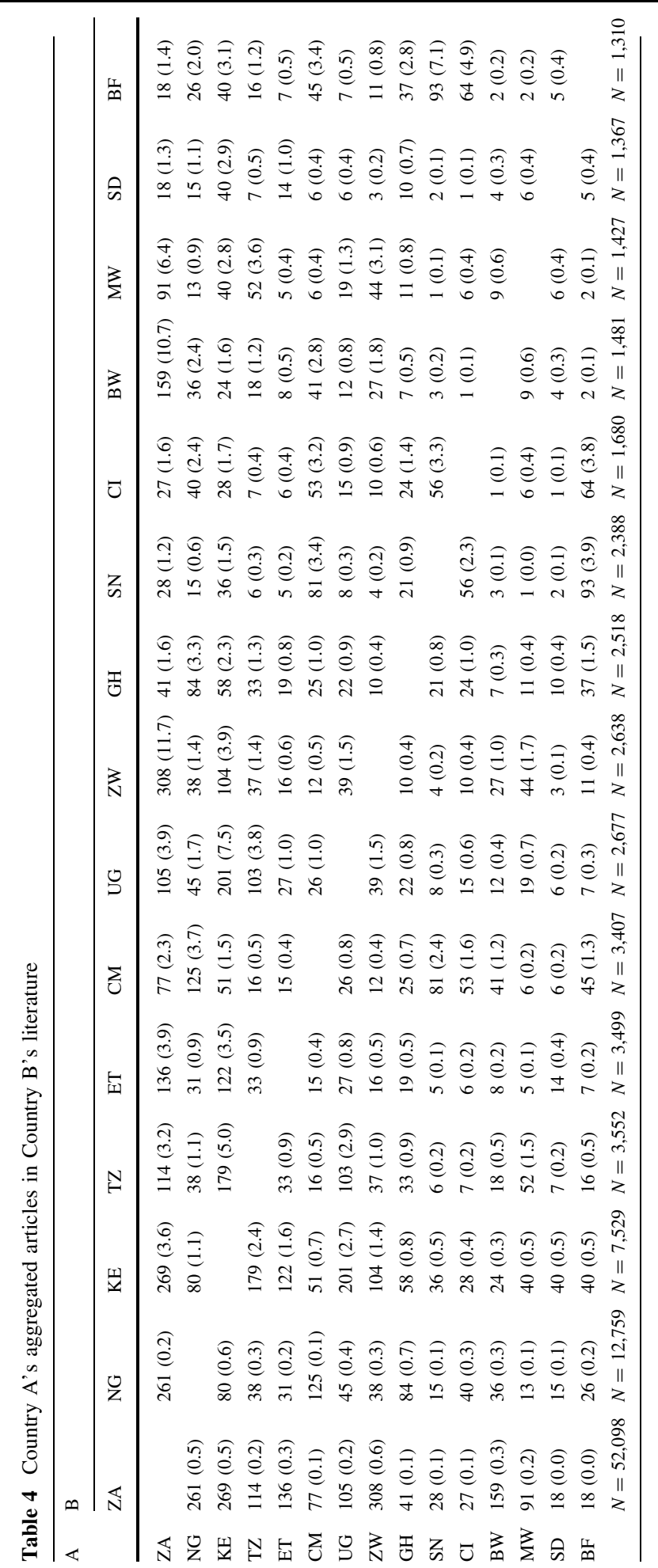


large number of students from other sub-Saharan African countries, especially at the postgraduate level.

\section{Contributions of selected sub-Saharan African countries to each other's total citations count}

The number of citations was assessed to determine a country's influence on another's citation count and, partly, citation impact. Table 5, which provides Country A's aggregated citation contribution to Country B's, shows that most countries contributed less than $1 \%$ of another country's total citations. For instance, contributions of each of the other countries to South Africa's citations count were each below 1\%. For its part, Nigeria received a citation boost of $1 \%$ and above each from only three countries, namely South Africa, Kenya and Cameroon. The highest citation contribution was made by South Africa to Botswana $(1,976,15.72 \%)$ followed by South Africa's contribution to Zimbabwe $(3,492$, $12.87 \%)$. Other relatively high citation contributions in the order of country A - country B (number of citations, \% of Country B's citations) are: Cote d'Ivoire - Burkina Faso $(1,455,11.65 \%)$, Kenya - Zimbabwe (2,182, 8.04\%), Tanzania - Uganda (2,874, $7.77 \%)$, Kenya - Tanzania (3,230, 7.35\%) and Uganda - Tanzania (2,874, 6.54\%).

In terms of sole contributions shown in Table 6 , the majority of countries did not contribute any citations to other countries on their own. Unlike in Table 5, where there were no zero entries, Table 6 recorded 53 entries reading zero citations, which implies that an article stands a better chance of being cited if it is authored by several countries or even individuals and institutions. This explains why all Table 6's entries were lower than Table 5's. Sole citation contributions recorded lower frequencies than aggregated contributions. In fact, only six entries recorded a percentage contribution of more than $1 \%$, with South Africa's sole contribution to Zimbabwe yielding 3.06\% of the latter's total citations, followed by South Africa's sole contribution to Botswana which stood at $381(3.03 \%)$ citations. Kenya contributed $286(1.01 \%)$ citations to Ethiopia. Seemingly, geographical proximity is playing a major role in one country's influence on another's citation count. South Africa's influence is more felt in the Southern African region while Kenya's influence is felt in the Eastern African region. The same goes with some of the countries located in Western Africa. For instance, Cameroon and Senegal contributed $47(0.38 \%)$ and $62(0.50 \%)$ citations to Burkina Faso, which is located in the same region.

\section{Contributions of selected sub-Saharan African countries to each other's citation impact}

The average cites per article, calculated as the total number of citations divided by country A's aggregated article contribution to country B's total number of articles, was computed to assess the influence of country A on country B's research impact. When benchmarked against the country's overall citation performance as indicated in the last row of Table 7, it was noted that South Africa's citation impact improved when the country collaborated with Kenya, Tanzania, Cameroon, Uganda, Zimbabwe, Ghana, Senegal, Cote d'Ivoire, Botswana, Sudan, and Burkina Faso. South Africa's citation impact decreased when the country collaborated with Nigeria, Ethiopia, and Malawi. Nigeria's citation impact on the other hand was higher when it collaborated with each of the countries under investigation. Kenya's collaboration with 10 out of 14 countries investigated in this study resulted in 


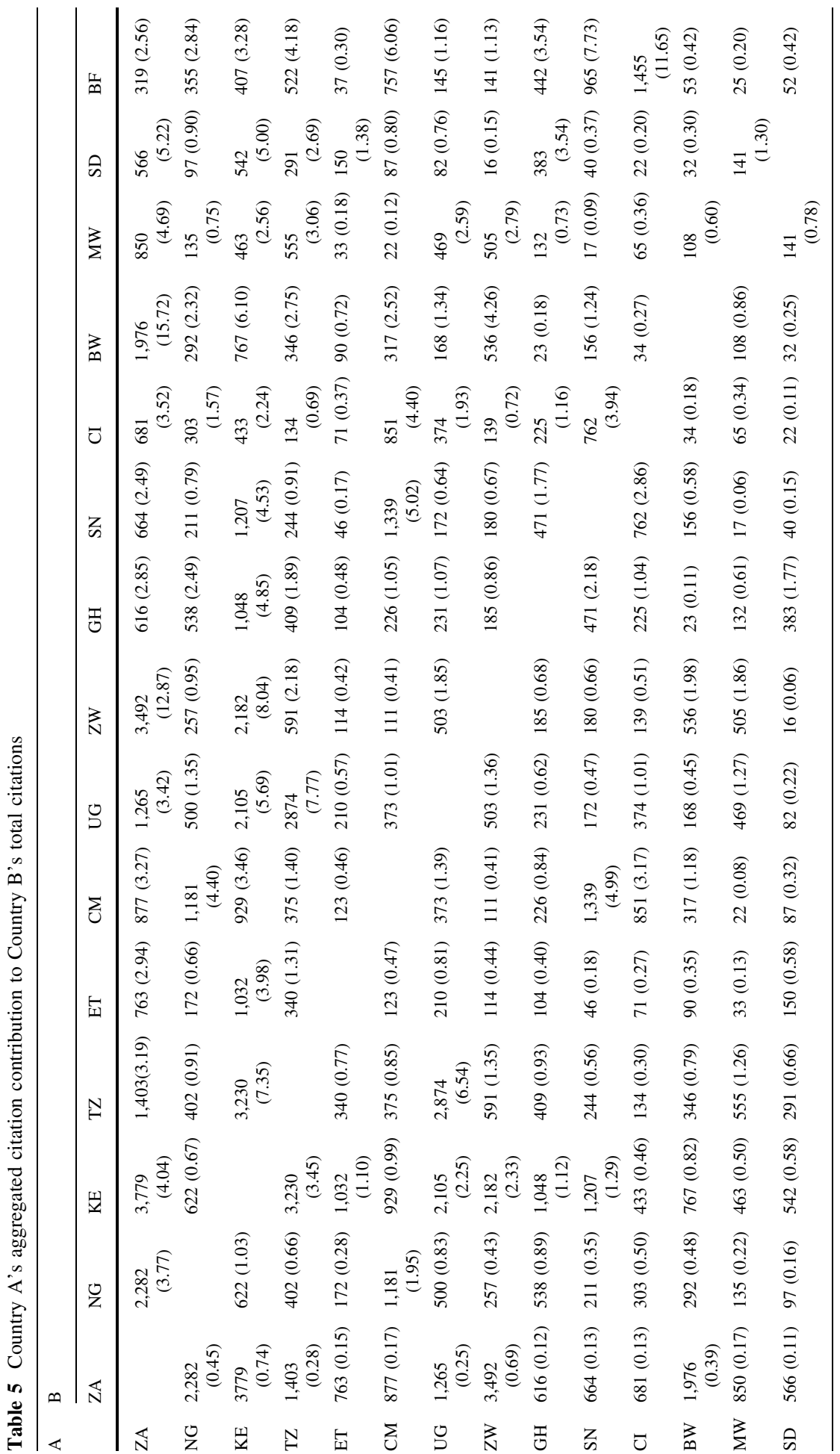




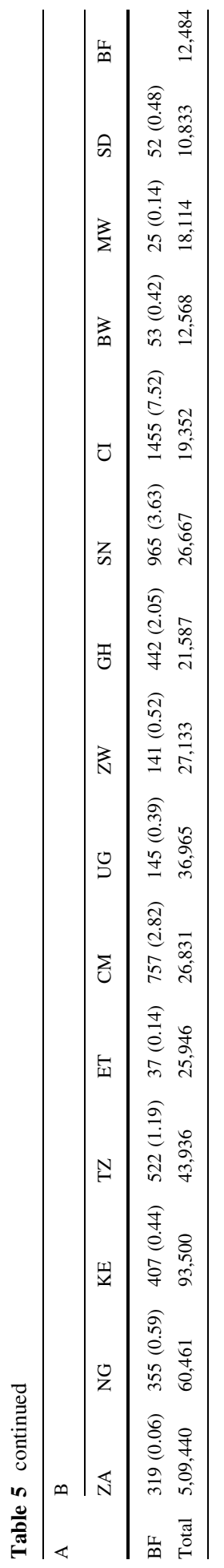

Springer 


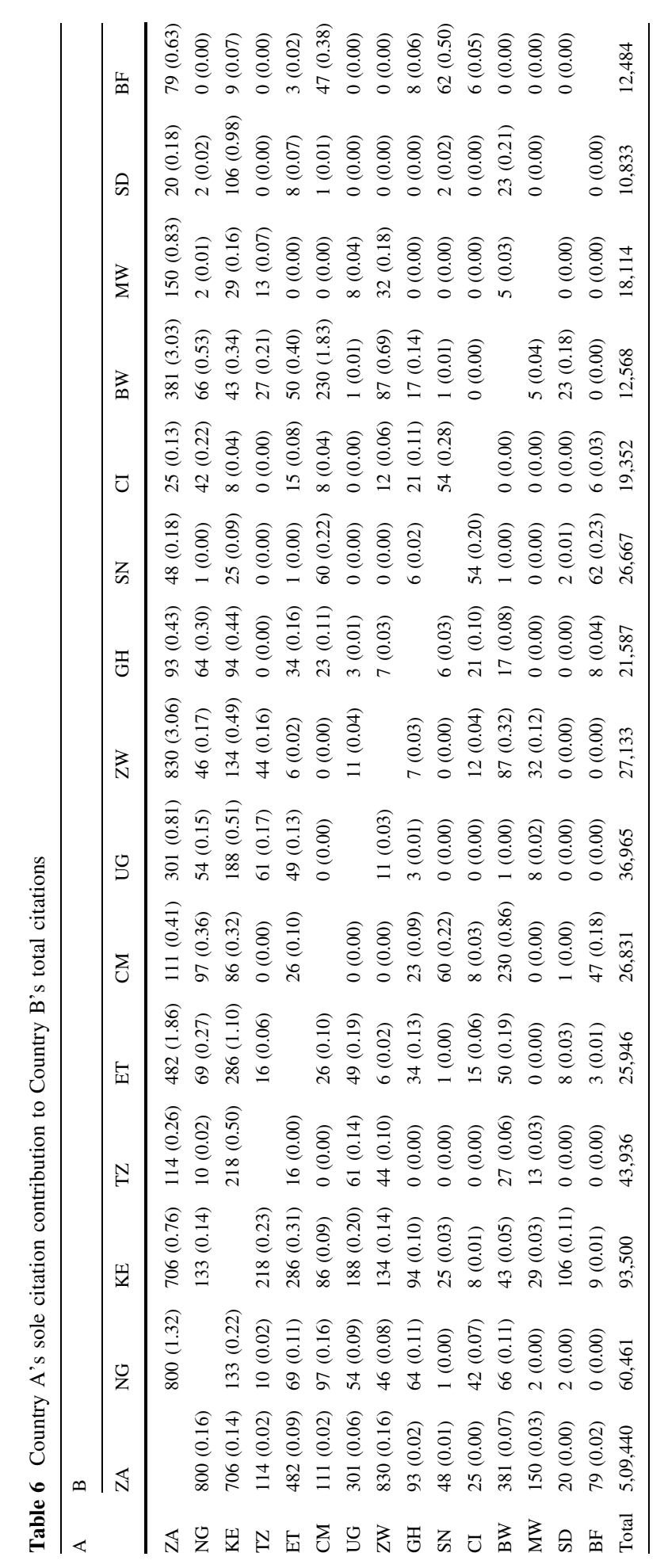




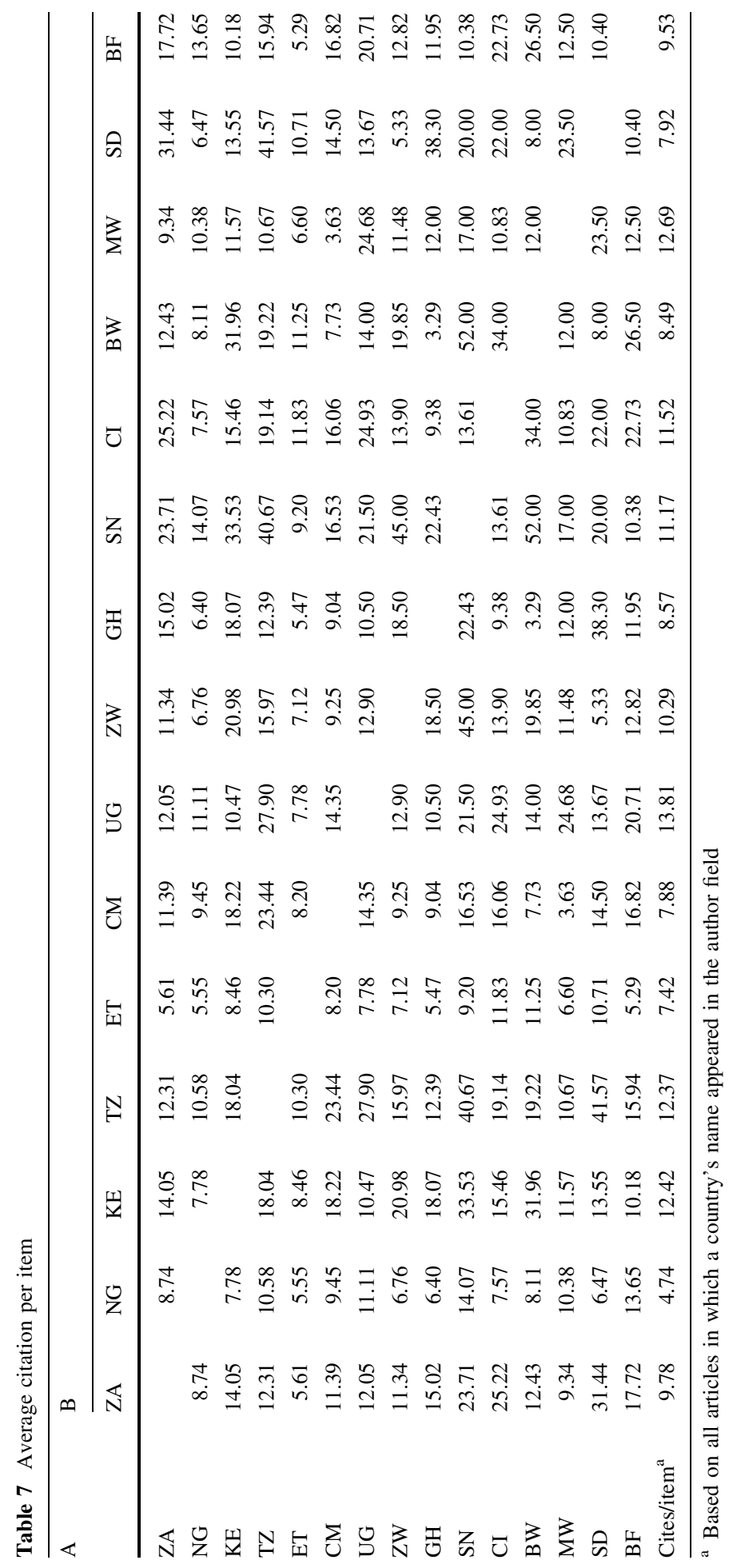


higher citation impacts, while Tanzania yielded higher citation impacts when it collaborated with $57 \%$ (i.e., 8) of the 14 countries. For its part, Cameroon's citation impact was lower than its aggregated average citations per article (i.e., 7.88) when the country collaborated with Botswana and Malawi. Uganda's total citations per article (i.e., 13.81) surpassed the average cites per article generated by the country's collaborative research with Kenya, Ethiopia, Zimbabwe, Ghana, and Sudan. Zimbabwe registered higher than its overall 10.29 citations per article in its collaborative research with South Africa, Kenya, Tanzania, Uganda, Ghana, Senegal, Cote d'Ivoire, Botswana, Malawi, and Burkina Faso. The highest number of citations per article (i.e., 52) was generated by Botswana and Senegal's research collaboration. Other collaborations that generated high citations per article include Senegal and Zimbabwe (45), Senegal and Tanzania (40.67), Ghana and Sudan (38.30), Kenya and Senegal (33.53), Botswana and Cote d'Ivoire (34), Botswana and Kenya (31.96), and South Africa and Sudan (31.44). Generally, most countries' citation impact was higher when the country in question collaborated with another which implies that collaborative research provides wider visibility which in turn increases the chances of the article being cited.

\section{Comparison of internal, regional and international research output and impact}

Table 8 illustrates the influence sub-Saharan African and foreign countries (combined) have on the research output (knowledge production) and citation impact of the selected countries. The Table compares sole authorship with (a) co-authorship with other subSaharan African countries; (b) co-authorship with foreign countries; and (c) co-authorship with all countries. It was noted that there was a general improvement in terms of the number of articles, citations count, average citations per article and $h$-index for each of the countries under investigation when the said countries collaborated with others. For example, South Africa's sole authorship produced 31,258 articles, 2,03,544 citations, 6.51 citations per article and an $h$-index of 83 . In its collaboration with other sub-Saharan African countries, South Africa's performance improved to 32,261 articles and 2,08,822 citations but dropped slightly in its citations per paper while its h-index remained the same. With regard to international (foreign) collaboration, South Africa improved its performance and recorded a total of 50,119 articles, 4,85,414 citations, average citations per paper of 9.69 and an h-index of 153 . Overall, the country's performance was as follows: 52,908 articles, 5,09,440 citations, 9.78 citations per article and h-index of 157. It therefore follows that South Africa performed better when it collaborated with foreign countries than with sub-Saharan African countries. For instance, a comparison of the average citations per paper in the two categories of internal authorship and co-authorship with sub-Saharan African countries reveals very little difference.

An examination of the number of publications reveals that South Africa's publications increased by a mere $3.21 \%$ when it collaborated with other African counterparts. Other countries recorded percentage growth rates in the number of publications as follows: Nigeria (5.29\%), Kenya (21.09\%), Tanzania (18.53\%), Ethiopia (17.40\%), Cameroon (22.50\%), Uganda (26.65\%), Zimbabwe (34.44\%), Ghana (12.67\%), Senegal (19.64\%), Cote d'Ivoire (15.24\%), Botswana (26.30\%), Malawi (31.77\%), Sudan (8.14\%), and Burkina Faso (35.98\%). When it came to international collaboration, South Africa's publications increased by $55.35 \%$ while Nigeria witnessed a growth rate of $26.68 \%$. The percentage growth rates of other countries were as follows: Kenya (170.36\%), Tanzania (288.37\%), Ethiopia (110.45\%), Cameroon (150.27\%), Uganda (213.64\%), Zimbabwe 


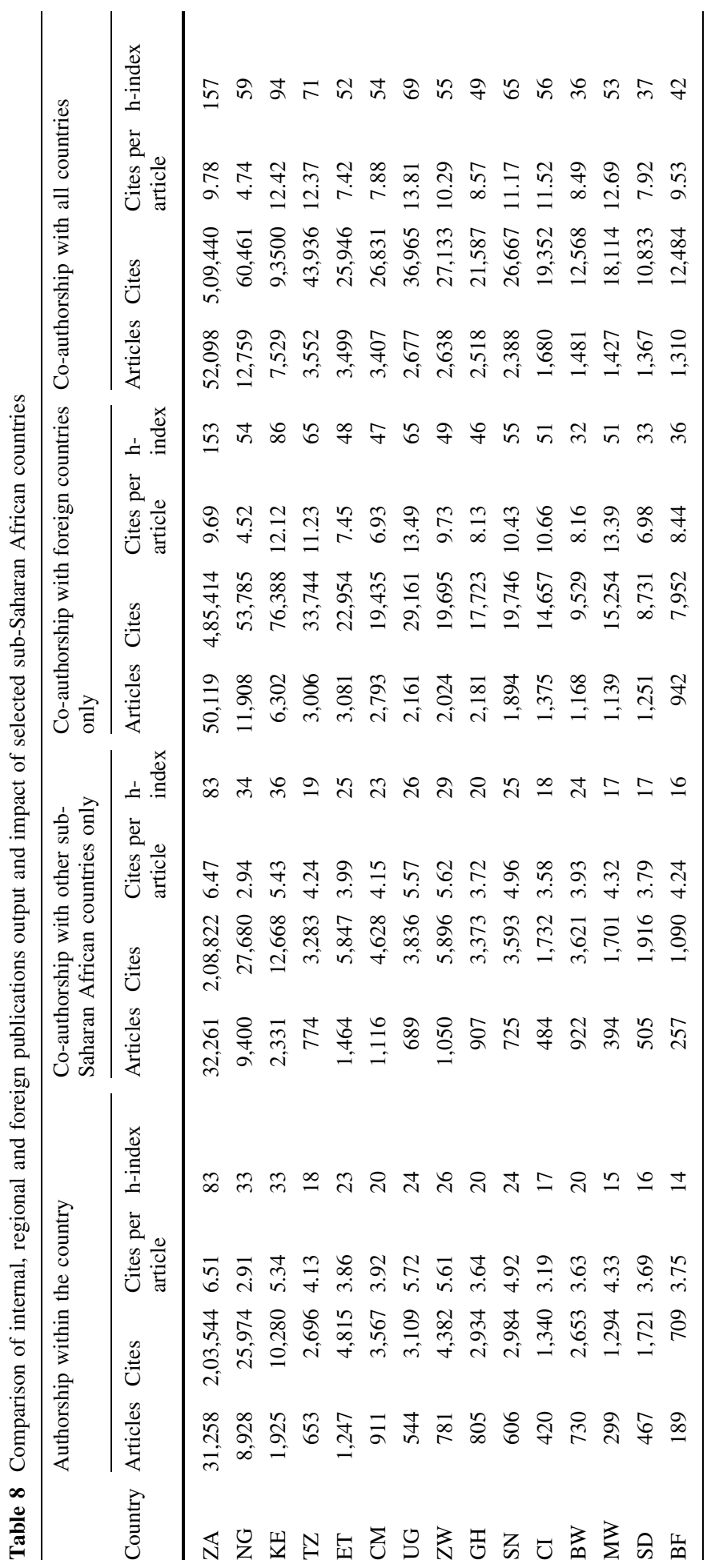


(92.76\%), Ghana (140.46\%), Senegal (161.24\%), Cote d'Ivoire (184.09\%), Botswana (26.68\%), Malawi (189.09\%), Sudan (147.72\%), and Burkina Faso (266.54). It should be noted therefore that apart from South Africa, Nigeria, Zimbabwe, and Botswana, which recorded a growth rate of less than $100 \%$ each in their collaboration with foreign countries, all the other countries surpassed $100 \%$, with Tanzania recording the highest growth rate of $288.37 \%$.

\section{Core/periphery model of selected country participants}

Upon normalization of the contents of Table 2, the generated data was subjected to a core/ periphery model analysis which produced the core/periphery class memberships shown in Fig. 2. Class 1, which comprised of South Africa, Nigeria, Kenya, Tanzania, Burkina Faso, Cameroon, and Uganda, formed what can be termed the core participants and contributors to each of the selected countries' total research output and therefore knowledge production. The other countries, such as Ethiopia, Ghana, Senegal, Cote d'Ivoire, Botswana, Malawi, Sudan, and Zimbabwe, were relegated to the periphery. South Africa generated the highest normalized score of 0.453 in its contribution to Botswana's research output, followed by its contribution to Ethiopia (0.306). Kenya's highest contribution was to Uganda (0.317), followed by its contribution to Sudan (0.292) and Ethiopia (0.275). It was noted that Ethiopia, Ghana, and Zimbabwe, which produced more articles than Burkina Faso, were categorized in Class 2 with the peripheral countries, simply because, overall, they were inconsistent in their contributions or research collaboration.

\section{Conclusion and recommendations}

This paper concludes that given the emphasis placed on teamwork and collective knowledge in the current knowledge economy (Skyrme 2002), it was not surprising to witness some form of collaborative knowledge production among the selected countries in subSaharan Africa. However, we also noted that knowledge production through collaborative research among the investigated countries is minimal. African countries contribute very little to each other's knowledge production in terms of research articles. The results

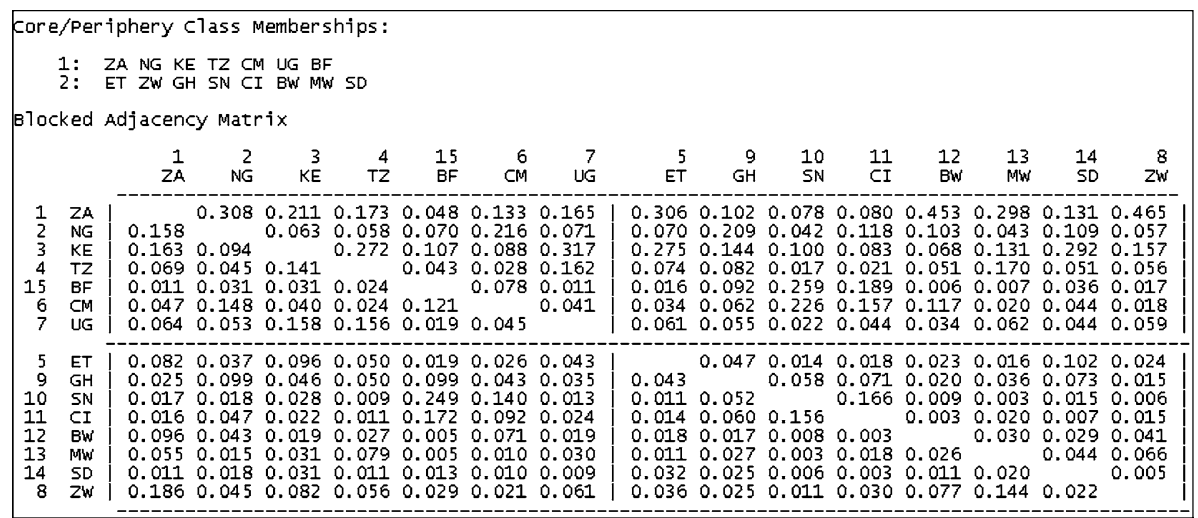

Fig. 2 Core/periphery model of research collaboration among selected sub-Saharan African countries 
presented in Section 3 above indicate that, with the exception of South Africa which contributed 11.7 and $10.7 \%$ towards the total research outputs of Zimbabwe and Botswana, respectively, sub-Saharan Africa countries contribute less than $10 \%$ of each other's total research output. Essentially, therefore, this implies minimal contributions in knowledge production and sharing among the sub-Saharan African countries. On the pattern of collaborative knowledge production, it emerged that countries engage in joint knowledge production based on their geographic proximity. In that respect, countries in the Southern African Development Community (SADC), East African Community (EAC) and the Economic Community of West African States (ECOWAS) largely contribute and share knowledge with other countries in their regions. The extent and proportion of foreign countries' knowledge production (and its impact) with sub-Saharan African countries was higher than continental knowledge production. South Africa, Nigeria, Zimbabwe, and Botswana recorded relatively low growth rates in their collaboration with foreign countries, a situation that may imply little foreign dependence in the countries' knowledge production activities.

This study's findings may also reflect the extent of knowledge sharing and exchange among scholars resident in the surveyed countries. Whereas it can be said that little knowledge exchange is taking place among African scholars, it seems that scholars based in foreign countries frequently share knowledge with their counterparts in sub-Saharan Africa. Narvaez-Berthelemot et al. (2002, p. 239) explain that just as is the case with "other developing regions of the world, little scientific co-authorship is found between countries, preference being given to collaboration with industrialized nations". Dependence on industrialized nations for the development of theories in different fields could also account for the pattern of knowledge production witnessed in this study.

With regard to research impact, which in this study reflects the impact that knowledge production through research collaboration in sub-Saharan Africa has in the scientific arena, it was found that citation impact of international collaboration is higher than that of continental collaboration. When assessed at face value, this means that research that is conducted in collaboration with scholars from foreign countries will have higher citation impact than that conducted among scholars resident in sub-Saharan Africa. This conclusion may not be entirely true as citation impact is influenced by several factors, including language of publication, journals in which the research is published, and databases used for data extraction and analysis. Nevertheless, in order for research conducted in Africa to have international impact, factors such as those outlined above should be taken into consideration.

Finally, knowledge co-production in sub-Saharan Africa should be encouraged by way of student and staff exchanges; visits by scholars to institutions in other countries should be encouraged; subjects or topics of common research interest should be identified and explored for possible collaborative research; researcher networks should be encouraged in sub-Saharan Africa; regional conferences where scholars can network should be held more frequently; and funding for collaborative research should be prioritized.

\section{References}

Cybermetrics Lab. Consejo Superior de Investigaciones Científicas (CSIC). (2010). Ranking of World universities: Top Africa. Accessed July 28, 2010, from http://www.webometrics.info/top100_continent.asp?cont=africa. Abramo, G., D'Angelo, C. A., \& di Costa, F. (2009). Research collaboration and productivity: Is there correlation? Higher Education, 57, 155-171. 
Adams, J., King, C., \& Hook, D. (2010). Global research report-Africa. Leeds, UK: Thomson Reuters. Accessed August 01, 2010, from http://researchanalytics.thomsonreuters.com/m/pdfs/globalresearch report-africa.pdf.

Aeberhard, A., \& Rist, S. (2008). Transdisciplinary co-production of knowledge in the development of organic agriculture in Switzerland. Ecological Economics, 68, 1171-1181.

Arocena, R., \& Sutz, J. (2001). Changing knowledge production and Latin American universities. Research Policy, 30, 1221-1234.

Arvanitis, R., Waast, R., \& Gaillard, J. (2000). Science in Africa: A bibliometric panorama using PASCAL database. Scientometrics, 47(3), 457-473.

Borgatti, S. P., Everett, M. G., \& Freeman, L. C. (2002). Ucinet 6 for Windows. Harvard: Analytic Technologies.

Boshoff, N. (2009). South-South research collaboration of countries in the Southern African Development Community (SADC). Scientometrics. doi:10.1007/s1119200901200.

Choung, J.-Y., Min, H.-G., \& Park, M.-C. (2003). Patterns of knowledge production: The case of information and telecommunication sector in Korea. Scientometrics, 58(1), 115-128.

Collazo-Reyes, F., Luna-Morales, M. E., Russell, J. M., \& Perez-Angon, M. A. (2010). Enriching knowledge production patterns of Mexican physics in particles and fields. Scientometrics. doi:10.1007/s 1119201002291.

Egbu, C. (2006). Knowledge production and capabilities - their importance and challenges for construction organizations in China. Journal of Technology Management in China, 1(3), 304-321.

Frenken, K. (2002). The geography of collaborative knowledge production: Entropy techniques and results for the European Union. Paper presented at 42nd European Congress Regional Science Association, Dortmund, Germany, August 27-31, 2002. Accessed July 28, 2010, from http://www-sre.wu-wien.ac. at/ersa/ersaconfs/ersa02/cd-rom/papers/029.pdf.

Gerber, R. E. (2005). The need for a shift in the South African educational research epistemological landscape. South African Journal of Higher Education, 19, 1395-1404.

Gibbons, M., Limoges, H., Schwartzman, S., Scott, P., \& Trow, M. (1994). The new production of knowledge: The dynamics of science and research in contemporary societies. London: SAGE Publications.

Godin, B., \& Gingras, Y. (2000). The place of universities in the system of knowledge production. Research Policy, 29, 273-278.

Hayashi, T., \& Fujigaki, Y. (1999). Differences in knowledge production between disciplines based on analysis of paper styles and citation patterns. Scientometrics, 46(1), 73-86.

Heinze, T., \& Kuhlmann, S. (2008). Across institutional boundaries? Research collaboration in German public sector nanoscience. Research Policy, 37, 888-899.

Hessels, L. K., \& van Lente, H. (2008). Re-thinking knowledge production: A literature review and a research agenda. Research Policy, 37, 740-760.

Hoekman, J., Frenken, K., \& Tijssen, R. J. W. (2010). Research collaboration at a distance: changing spatial patterns of scientific collaboration within Europe. Research Policy. doi:10.1016/j.respol.2010.01.012.

Hoekman, J., Frenken, K., \& van Oort, F. (2009). The geography of collaborative knowledge production in Europe. Annals of Regional Science, 43, 721-738.

Huff, A. S. (2000). 1999 Presidential address: Changes in organizational knowledge production. The Academy of Management Review, 25(2), 288-293.

Imeda, S. N. (2005). The idea of a South African university and implications for knowledge production. South African Journal of Higher Education, 19, 1405-1418.

Jacob, M. (2000). 'Mode 2' in context: The contract researcher, the university and the knowledge society. In M. Jacob \& T. Hellstrom (Eds.), The future of knowledge production in the academy. Buckingham: The Society for Research into Higher Education.

Jansen, D., von Gortz, R., \& Heidler, R. (2010). Knowledge production and the structure of collaboration networks in two scientific fields. Scientometrics, 83, 219-241.

Klitkou, A., Patel, P., \& Campos, A. (2009). Linkages between technical universities and industry measured by co-authorship and patent data. Accessed March 30, 2010, from http://muteis.infonomics.nl/ MEIDE/papers/2009/1235891044_AD.pdf.

Le Grange, L. (2005). Reflexivity and new modes of knowledge production: The case of the human and social sciences. South African Journal of Higher Education, 19, 1444-1455.

Lundberg, J. (2006). Bibliometrics as a research assessment tool-impact beyond the impact factor. Stockholm: Karolinska Institutet. Accessed July 27, 2010, from http://diss.kib.ki.se/2006/917140-965-3/thesis.pdf.

Moravec, J. W. (2007). A new paradigm of knowledge production in Minnesota Higher Education: A Delphi study. Ann Arbor, MI: ProQuest Information and Learning Co. 
Narvaez-Berthelemot, N., Russell, J. M., Arvanitis, R., Waast, R., \& Gaillard, J. (2002). Science in Africa: An overview of mainstream scientific output. Scientometrics, 54(2), 229-241.

Onyancha, O. B. (2009). South Africa's regional and international collaboration: An informetric study of participating countries, 1986-2005. In D. N. Ocholla \& D. Jacobs (Eds.), Proceedings of the DLIS 10th Annual Conference, 2009 (pp. 176-198). KwaDlangezwa, South Africa: University of Zululand, Department of Information Studies. Accessed July 31, 2010, from http://www.lis.uzulu.ac.za/research/ conferences/10th\%20DLIS\%20conferenceFeb\%202010.pdf.

Onyancha, O. B., \& Ocholla, D. N. (2007). Country-wise collaborations in HIV/AIDS research in Kenya and South Africa, 1980-2005. LIBRI, 57, 239-254.

Prpic, K. (2007). Changes of scientific knowledge production and research productivity in a transitional society. Scientometrics, 72(3), 487-511.

Ranga, L. M., Debackere, K., \& von Tunzelmann, N. (2003). Entrepreneurial universities and the dynamics of academic knowledge production: A case study of basic vs. applied research in Belgium. Scientometrics, 58(2), 301-320.

Russell, J. M., \& Rousseau, R. (n. d.). Bibliometrics and institutional evaluation. Accessed June 26, 2010, from http://www.vub.ac.be/BIBLIO/itp/lecturers/ronald_rousseau/ronald_roussea_stim1_bibliometrics_ russell.pdf.

Schneider, B., Schalliol, D., Makela, S., \& McDonald, S.-K. (2006). Knowledge production and the public interest. The American Sociologist, 37(2), 96-112.

Skyrme, D. J. (2002). The 3Cs of knowledge sharing: Culture, co-opetition and commitment. Accessed July 20, 2010, from http://www.skyrme.com/updates/u64_f1.htm.

Sooryamoorthy, R. (2009). Collaboration and publication: How collaborative are scientists in South Africa? Scientometrics, 80(2), 419-439.

Wessels, J. S. (2006). The challenges of knowledge production by researchers in public administration: A South African perspective. South African Journal of Higher Education, 19, 1499-1515. 